\title{
SOLICITUD DE MEDIDAS CAUTELARES URGENTES ANTE EL TRIBUNAL CONSTITUCIONAL FEDERAL ALEMÁN CONTRA DISPOSICIONES DEL GOBIERNO DE BAVIERA RELATIVAS A LA COVID-19
}

\section{REQUEST FOR EXPEDITED PRECAUTIONARY MEASURES BEFORE THE GERMAN FEDERAL CONSTITUTIONAL COURT AGAINST PROVISIONS OF THE GOVERNMENT OF BAVARIA RELATING TO COVID-19}

\author{
Gonzalo Dell'Orsi' \\ DOI: https://doi.org/10.37767/2591-3476(2021)11 \\ Comentario a \\ Tribunal Constitucional Federal Alemán \\ Disponible en \\ https://bit.ly/3BhviZo
}

\section{RESUMEN:}

Con motivo de la Pandemia Covid-19, los gobiernos de los distintos Estados han tomado medidas tendientes a proteger a su población. Muchas de ellas, fueron calificadas por los propios destinatarios como extremas, innecesarias y hasta inconstitucionales. Ello motivó, un sinnúmero de recursos presentados ante la administración de justicia. En Alemania, el Tribunal Constitucional Federal, se expidió en reiteradas oportunidades rechazándolos por inadmisibilidad formal. Sin embargo, con fecha 7 de abril del 2020, la cámara 3 admitió formalmente una solicitud de medida cautelar presentada por un particular, lo que implicó para el Tribunal tratar su procedencia. La medida cautelar so-

1 Abogado (Universidad Nacional de Córdoba); Magister en Derecho alemán y doctorando (Ludwig Maximilians Universität de Munich). Prosecretario del Superior Tribunal de Justicia de la Provincia de Tierra del Fuego. gdellorsi@gmail.com. ORCID iD:https://orcid.org/0000-0002-0504-9052 
licitada pretendía dejar sin efecto las disposiciones temporales del Gobierno de Baviera sobre medidas de protección contra la pandemia. El Tribunal no hizo lugar a la solicitud por considerarla infundada, priorizando el derecho a la vida y a la salud, sobre otros derechos fundamentales.

\section{ABSTRACT}

Due to the coronavirus pandemic, the governments of different countries have taken measures to protect their population. Many of these measures were considered extreme, unnecessary and even unconstitutional by those to whom they were addressed. This has led to numerous appeals to the courts. In Germany, the Federal Constitutional Court has repeatedly rejected them as formally inadmissible. However, on 7 April 2020, Chamber 3 formally admitted an application for an interim injunction filed by a private individual, which meant that the Court had to consider whether it was admissible. The requested interim injunction was aimed at annulling the Bavarian government's temporary provisions on pandemic security measures. The Court rejected the application as unfounded, prioritizing the right to life and health over other fundamental rights.

\section{ZUSAMMENFASSUNG}

Aufgrund der Covid-19 Pandemie haben die Regierungen verschiedener Staaten Maßnahmen zum Schutz ihrer Bevölkerung ergriffen. Viele von ihnen wurden von den betroffenen Personen als extrem, unnötig, und sogar verfassungswidrig empfunden. Dies führte zu unzähligen Beschwerden bei der Justizverwaltung. In Deutschland wurden diese wiederholt wegen formaler Unzulässigkeit vom Bundesverfassungsgericht abgewiesen. Am 7. April 2020 hat die Kammer 3 jedoch formell einen von einer Einzelperson eingereichten Antrag auf eine Einstweilige Anordnung zugelassen, was bedeutete, dass das Gericht sich mit deren Ursprung befassen musste. Die beantragte Einstweilige Anordnung sollte die vorläufigen Bestimmungen der bayerischen Regierung zu Schutzmaßnahmen gegen die Pandemie außer Kraft setzen. Das Gericht gab dem Antrag nicht statt, da es ihn für unbegründet hielt und dem Recht auf Leben und Gesundheit Vorrang vor anderen Grundrechten einräumte.

PALABRAS CLAVE: CLAVE: Medidas cautelares, Proceso de urgencia, Tribunal Constitucional Federal Alemán, Derechos fundamentales, Medidas de protección.

KEY WORDS: Precautionary measure, Expedited processing, German Federal Constitutional Court, Fundamental Rights, Protection measures.

SCHÜSSELWÖRTER: Einstweilige Anordnung, Eilrechtsschutzverfahren, Bundesverfassungsgericht, Grundrechte, Schutzmaßnahmen 


\section{Introducción}

La sentencia analizada se da en un contexto de pandemia, en el cual los Estados adoptan diversas medidas tendientes a paliar las consecuencias de la enfermedad. El virus que en la actualidad ataca a la población mundial se conoce con el nombre técnico SARS-CoV$2^{2}$ (argentina.gob.ar/salud/coronavirus/preguntasfrecuentes), y provoca la enfermedad que conocemos como COVID-19. Esta, se caracteriza por su gran propagación "a través de pequeñas partículas líquidas expulsadas por una persona infectada por la boca o la nariz al toser, estornudar, hablar, cantar o respirar. Las partículas tienen diferentes tamaños, desde las más grandes llamadas gotículas respiratorias, hasta las más pequeñas, o aerosoles" (Organización Mundial de la Salud). Es por ello que las principales recomendaciones son evitar los contactos directos con personas, y desinfectar los materiales que tocamos y alimentos que consumimos. Un dato importante es que la enfermedad no tiene tratamiento, sino que lo que puede tratarse son los síntomas que provoca, con el solo objetivo de hacerlos desaparecer, o al menos reducirlos. Por otro lado, existen personas que por distintas circunstancias conforman grupos de riesgo, lo que los ubica en una situación de mayor vulnerabilidad frente al virus. A nivel global fueron reportados al día 21 de julio de 2021, un total 190.860 .860 casos confirmados de COVID-19, incluidos 4.101 .414 casos de muerte $^{3}$ (Organización Mundial de la Salud).

Las medidas adoptadas se basan en la epidemiología clásica: "identificar y aislar a los casos, seguir a los contactos y establecer restricciones, incluyendo la cuarentena, en la movilidad, evitando eventos en los que se produzcan aglomeraciones de personas" (Antoni Trilla, 2020). En este intento por cuidar la salud pública, encontramos medidas de lo más variado, desde el uso de tapabocas, hasta el cierre de fronteras entre países, pasando por restricciones a la circulación y al desarrollo de actividades sociales.

En el caso de Argentina, las medidas adoptadas por el Gobierno Nacional ${ }^{4}$ comenzaron como medidas de supervisión de acciones en el Aeropuerto de Ezeiza en febrero de 2020 y protocolos de acción para vuelos que llegaban al país en marzo del mismo año. Sin embargo, al poco correr de los días, las medidas fueron multiplicándose, y abarcando cada vez más ámbitos de la vida privada de las personas. Por ejemplo, la suspensión del dictado de clases presenciales en todas las escuelas del país el 15 de marzo de 2020, que si bien en un principio regía por solo 14 días, fue renovándose durante meses, o el cierre de fronteras el 16 de marzo del mismo año. Otra medida que no puede dejar de mencionarse es el aislamiento social, preventivo y obligatorio para toda la población, que comenzó el 19 de marzo de 2020, extendiéndose en algunas ciudades -según los índices de contagio en las distintas Provincias- durante meses.

En Alemania una de las primeras medidas adoptadas fue el aislamiento por 15 días a las personas que regresaban en vuelos de Wuhan, China, con fecha 31 de enero de 2020, junto a otras relativas a protocolos en aeropuertos internacionales. ${ }^{5}$ Sin embargo, con el correr del tiempo -al igual que sucedió en Argentina-, Alemania fue adoptando más medidas de protección, y con mayor intervención en la vida de las personas. Así, por

\footnotetext{
2 “Se trata de una nueva variante de la familia 'los coronavirus', los que pueden causar infecciones respiratorias que van desde un resfrío común hasta enfermedades más graves".

3 Particularmente en Alemania fueron reportados al día 21 de julio de 20213.746 .410 casos confirmados de Covid-19 y 91.397 muertes. En Argentina, a la misma fecha se reportaron 4.769 .142 casos confirmados y 101.955 muertes. Organización Mundial de la Salud (OMS).

4 Medidas contra el Covid-19 en Argentina. https://www.argentina.gob.ar/coronavirus/medidas-gobierno

5 Crónica de medidas del ministerio de salud de Alemania y acontecimientos relacionados con la pandemia. https://www.bundesgesundheitsministerium.de/ coronavirus/chronik-coronavirus.html Todas las citas originales del alemán han sido traducidas al castellano por el autor.
} 
ejemplo, comenzaron a cerrarse locales comerciales, bajo entendimiento de que la salud de las personas es más importante que los intereses económicos. Con esa misma lógica, comenzaron las restricciones a la movilidad personal, como prohibiciones a salir de los hogares en ciertas franjas horarias o sin motivos justificados, o restricciones sociales, como reunirse con otras personas.

Estas, y otras medidas, restringen el goce de ciertos derechos fundamentales, por lo que algunos afectados acudieron a instancias judiciales con el objetivo de obtener una respuesta favorable que les ponga fin, y reestablezca el pleno goce de sus derechos. Como fue adelantado, Alemania no se encuentra al margen de esta situación, por lo que sus tribunales también debieron expedirse sobre este tipo de reclamos.

El presente trabajo es un comentario de la sentencia 1 BvR 755/20 (Beschluss der 3. Kammer des Ersten Senats vom 7. April 2020) del Tribunal Constitucional Federal Alemán ${ }^{6}$ (en adelante también Tribunal o Tribunal Constitucional), por la cual, admitió formalmente la solicitud de una persona que se veía afectada por las medidas adoptadas por el Gobierno de Baviera, para luego -analizado el caso-, no hacer lugar al pedido. En primer lugar, presentaré las medidas adoptadas por el gobierno de Baviera (II), seguidamente el reclamo del recurrente y los derechos vulnerados (III). Dedicaré un apartado a desarrollar las particularidades del proceso en el presente caso (IV), para luego referir al actuar concreto del Tribunal y su decisión (V). Finalmente, una escueta conclusión sobre la sentencia (VI).

\section{Medidas adoptadas por el Gobierno de Baviera}

El art. 20 de la Ley Fundamental Alemana7 comienza diciendo "(1) La República Federal de Alemania es un Estado federal democrático y social" (Artikel 20 GG), lo que entre otras cosas significa que en paralelo al Gobierno Federal, existen tantos gobiernos locales como Estados conforman la Federación. Es decir que dentro de cada Estado Federado, encontraremos al igual que en la Federación, la división horizontal de poderes -Ejecutivo, Legislativo y Judicial- (Klaus Michael Miebach, 2001). La competencia de los Estados Federados está establecida en el art. 30 de la Ley Fundamental: "El ejercicio de las competencias estatales y el cumplimiento de las funciones estatales competen a los Estados siempre que la presente Ley Fundamental no disponga o admita una disposición en contrario" (Artikel 30 GG).

Producto de la coexistencia entre ambos órdenes, existen reglas de distribución de competencias legislativas entre la Federación y los Estados, donde podemos diferenciar la legislación exclusiva de la Federación, y la legislación concurrente entre esta y los Estados. La regla principal está establecida en el art. 70 inc. (1), el que establece que "Los Estados poseen el derecho de legislar en tanto la presente Ley Fundamental no lo confiera a la Federación" (Artikel 70 Abs. 1 GG). El art. 74 de la Ley Fundamental enumera la legislación concurrente entre el Estado Federal y los demás Estados, y en su inc. (19) establece en particular la legislación para medidas contra enfermedades humanas (Artikel 74 Abs. 19 GG). Existe asimismo una Ley Federal de Protección contra Infecciones ${ }^{8}$, la que establece distintas medidas para "prevenir las enfermedades transmisibles entre seres humanos, detectar las infecciones a tiempo, y prevenir su propagación" (\$1 Abs. 1 IfSG). Por eso, en razón de la existencia de una Ley Federal que ya regula tal situación, existe cierta controversia en relación a la potestad de los Estados para legislar medidas contra enfermedades.

6 En alemán Bundesverfassungsgericht (BVerfG).

7 Ley Fundamental de la República Federal de Alemania. En alemán Grundgesetz (GG).

8 En alemán Gesetz zur Verhütung und Bekämpfung von Infektionskrankheiten beim Menschen, Infektionsschutzgesetz (IfSG). 
El presente trabajo no desarrolla dicha controversia, ya que el objetivo no es analizar la constitucionalidad de las medidas dictadas por el Gobierno de Baviera, sino el proceso mediante el cual el Tribunal Constitucional desestimó el pedido urgente de medidas cautelares. Corresponde aclarar asimismo que al tratarse de un proceso de urgencia, el Tribunal no se expidió sobre la constitucionalidad de las medidas atacadas por el recurrente, sino que ello quedó pendiente para una próxima sentencia, limitándose en esta oportunidad a determinar si correspondía o no el otorgamiento de las medidas cautelares.

En función al Art. 74 inc. 19 y art. 72 inc. 1 de la Ley Fundamental, el 25 de marzo de 2020, el Estado de Baviera sancionó su propia Ley de Protección contra Infecciones. ${ }^{9}$ Asimismo, dictó más de 12 reglamentos sobre medidas de protección contra infecciones. ${ }^{10}$

Las medidas en particular contra las que presentó su solicitud el recurrente son:

a) Disposiciones generales del ministerio de salud y asistencia, y del ministerio de familia, trabajo y social. ${ }^{11}$

1. Prohibición de eventos y reuniones sociales, incluso las religiosas o de culto, sin importar cual sea.

2. Prohibición de actividades de locales destinados a la recreación, o no considerados de necesidad básica. Están incluidos (saunas, cines, salas de reuniones y eventos, clubes, bares y discotecas, salas de juegos, teatros, salas de clubes, burdeles, lagos, visitas guiadas, salas deportivas, campos deportivos y de juegos, gimnasios, bibliotecas, piscinas, centros de bienestar, balnearios, escuelas de danza, parques de animales, lugares de ocio, centro de apuestas, centros de formación, escuelas, escuelas de música y residencias juveniles, albergues juveniles y residencias escolares).

3. Prohibición de establecimientos gastronómicos de todo tipo, incluidos restaurantes en espacios cerrados y zonas abiertas. Están excluidos entre las 06:00 y 15:00 los locales que vendan alimentos para llevar o hagan envíos a domicilio (estos últimos sin límite de tiempo).

4. Colocación de carteles en parques y espacios verdes indicando la necesidad de las personas de mantener una distancia mínima de un metro y medio entre ellas.

5. Prohibición de apertura de locales de ventas al menor de todo tipo de productos, salvo los considerados esenciales.

b) Medidas ordenadas por el Ministerio de Salud y Asistencia de Baviera el 24 de marzo de 2020 para restringir la circulación de personas con motivo de la pandemia. ${ }^{12}$

1. Recomendación a todas las personas a reducir al mínimo absolutamente necesario el contacto físico y social con otras personas, que no sean las que habitan la misma casa.

2. Prohibición de explotación para los establecimientos gastronómicos, con excepción de las actividades que ofrezcan alimentos para retirar o enviar.

3. Prohibición de asistencia a hospitales y centros de salud en los que se establecieron centros de atención epidemiológicos, con excepción a la atención de partos e internaciones de niños recién nacidos. Prohibición de visitas a personas internadas; a personas discapacitadas internadas en lugares donde se presta -día y noche- la

9 En alemán Bayerisches Infektionsschutzgesetz (BayIfSG).

10 En alemán Infektionsschutzmaßnahmenverordnung.

11 Bekanntmachung des Bayerischen Staatsministeriums für Gesundheit und Pflege und des Bayerischen Staatsministeriums für Familie, Arbeit und Soziales vom 16.03.2020, Az. 51-G8000-2020/122-67 zuletzt geändert durch Bekanntmachung vom 17.03.2020, Az. Z6a-G8000-2020/122-83.

12 2126-1-4-G Bayerische Verordnung über eine vorläufige Ausgangsbeschränkung anlässlich der Corona-Pandemie vom 24. März 2020. 
asistencia necesaria; servicios ambulatorios de asistencia a pacientes; y visitas en hogares de ancianos y geriátricos.

4. Aceptación de salidas de los hogares solo según los motivos establecidos.

5. Los motivos válidos son los siguientes: a) el ejercicio de la profesión u oficio; b) la recepción de medicamentos o visitas a médicos; c) buscar alimentos y otros elementos de necesidad básica; d) visitar a la pareja, o personas mayores, enfermas, o discapacitadas (pero no internadas); e) el acompañamiento a personas que lo necesitan y personas menores de edad; f) asistencia a sepelios y entierros para círculos familiares; $g$ ) deportes y ejercicio en el aire libre; h) asistencia a animales.

6. La policía deberá controlarlo, y solicitar los motivos.

c) Medidas ordenadas por el Ministerio de Salud y Asistencia de Baviera con motivo de la pandemia de Corona Virus el 27 de marzo de $2020 .^{13}$

1. Prohibición de eventos y reuniones, incluidas las que se dan con motivo de un culto o religión. Podrá sin embargo hacerse una excepción, cuando la autoridad de control considere que se cumplen los protocolos pertinentes para evitar la propagación del virus.

2. Prohibición de actividades comerciales que no sean de necesidad básica, por lo que solo se habilita la explotación de locales que vendan alimentos y bebidas, los bancos, las farmacias, las ópticas, las sucursales de correo, las veterinarias y las estaciones de servicio (entre otros de una lista elaborada por el gobierno). Estos deberán hacer observar el distanciamiento de un metro y medio entre las personas, y no podrán tener a más de diez en la zona de espera. Se establece la prohibición de establecimientos gastronómicos de cualquier tipo, incluidos al aire libre. La única excepción es para los establecimientos limitada a la entrega de alimentos, ya sea mediante retiro, o envío a domicilio. Por último, se suspende toda la explotación hotelera y gastronómica relativa al turismo.

3. Prohibición de asistencia a hospitales y centros de salud en los que se establecieron centros de atención epidemiológicos, al igual que en la reglamentación anterior (p.3 del apartado b).

Como se observa, las medidas adoptadas por el Gobierno de Baviera implican serias restricciones al libre goce y ejercicio de derechos, como el de movilidad o libre circulación, el libre desarrollo de la personalidad, el de reunión, o el de ejercicio de una profesión u oficio. El fundamento para ello, es la necesidad de reducir al mínimo posible los contactos entre las personas, para así poder consecuentemente reducir los índices de contagio.

Surge entonces una colisión entre los derechos fundamentales, cuyo ejercicio fue limitado, y el derecho a la salud y a la vida, también fundamentales, y que el Estado debe garantizar. En esta lógica, el Gobierno de Baviera decidió restringir los primeros, para asegurar los segundos.

\section{El reclamo del recurrente y los derechos vulnerados}

El solicitante entiende que una prohibición de juntarse con amigos, de visitar a sus padres, de protestar, o de conocer nuevas personas, es extrema, y por ello solicita una medida cautelar urgente. ${ }^{14}$ Fundamenta su solicitud principalmente en dos artículos de

13 2126-1-4-G, 2126-1-5-G Bayerische Verordnung über Infektionsschutzmaßnahmen anlässlich der Corona-Pandemie (Bayerische Infektionsschutzmaßnahmenverordnung - BayIfSMV) vom 27. März 2020.

14 En alemán Einstweilige Anordnung. 
la Ley Fundamental, que establecen los derechos a la libertad de acción y de desarrollo personal (art. 2) y a la libertad de reunión (art. 8).

Art. 2 de la Ley Fundamental Alemana (Libertad de acción y de desarrollo personal): "Inc. 1. Toda persona tiene el derecho al libre desarrollo de su personalidad siempre que no viole los derechos de otros ni atente contra el orden constitucional o la ley moral. Inc. 2. Toda persona tiene el derecho a la vida y a la integridad física. La libertad de la persona es inviolable. Estos derechos sólo podrán ser restringidos en virtud de una ley" (Artikel 2 GG). Art. 8 de la Ley Fundamental Alemana (Libertad de reunión): "Inc. 1. Todos los alemanes tienen el derecho de reunirse pacíficamente y sin armas, sin notificación ni permiso previos. Inc. 2. Para las reuniones en lugares abiertos, este derecho puede ser restringido por la ley o en virtud de una ley" (Artikel 8 GG).

Igualmente, refiere a las normas que procesalmente habilitan la vía del reclamo intentado. El art. 32 Inc. 1. del Estatuto del Tribunal Constitucional Federal Alemán ${ }^{15}$, establece que en un litigio, el Tribunal Constitucional Federal puede regular una situación mediante medida cautelar, si ello deviene necesario de manera urgente para evitar graves desventajas, prevenir amenazas de violencia o por otra razón importante para el bien común (§ 32 Inc. 1 BVerfGG). Por su parte, el art. 90 Inc. 1 del mismo Estatuto, establece que toda persona puede presentar un recurso constitucional al Tribunal Constitucional Federal Alemán, con el argumento de ver violentado un derecho fundamental, o uno de los derechos establecidos en los arts. 20 inc. 4, 33, 38, 101, 103, y 104 de la Ley Fundamental (§ 90 Inc. 1 BVerfGG).

La admisibilidad del recurso, se regula en el segundo inciso del art. 90, de donde se desprende como requisito, que el recurrente debe haber agotado la vía procesal ordinaria. Asimismo, agrega en una segunda oración que, "no obstante, el Tribunal puede decidir de inmediato sobre un recurso constitucional, presentado antes de haberse agotado la vía procesal, toda vez que la cuestión sea de interés público, o que de exigirse el agotamiento de la vía anterior, el recurrente sufriría un daño grave e irreparable" (§ 90 Inc. 2 BVerfGG).

\section{Particularidades del proceso}

El recurrente presentó una solicitud de medida cautelar urgente, lo que se entiende como un acuerdo provisional, tendiente a garantizar la eficacia y viabilidad de una posterior decisión del Tribunal Constitucional sobre el fondo de la cuestión, particularmente para impedir situaciones irreversibles (Bundesverfassungsgericht.de/Verfahren). De esta manera, el Tribunal Constitucional Federal Alemán puede, sin resolver sobre la constitucionalidad de las medidas adoptadas por el Gobierno de Baviera, suspender su aplicación.

Para el dictado de una medida cautelar no es necesario que exista pendiente de resolución un proceso principal, sino que este puede presentarse también con posterioridad. El art. 32 del Estatuto del Tribunal Constitucional Federal Alemán regula este tipo de medidas, y establece que la adopción de una medida cautelar presupone la necesidad urgente, para evitar graves perjuicios, amenazas violentas, o cualquier otra consecuencia contra el interés general. Por ello, el criterio de examen seguido para estos procesos es distinto al utilizado en un procedimiento de declaración de inconstitucionalidad. Aquí lo decisivo no es la perspectiva de éxito del procedimiento principal, sino la evaluación de 
impacto que tienen las consecuencias. Estas son: las consecuencias que se derivarían de la imposibilidad de dictar una medida provisional pero prosperara el asunto principal en el futuro, se sopesarán con las desventajas que se derivarían de dictar la medida provisional sin prosperar el asunto principal (Bundesverfassungsgericht.de/Verfahren).

No es la primera oportunidad en que el Tribunal Constitucional Federal Alemán se expide en un proceso de medidas cautelares solicitadas contra medidas restrictivas dispuestas con motivo de la pandemia Covid-19. Sin embargo, la particularidad de esta sentencia es que el Tribunal no desestimó la solicitud por mera falta de formalidad, sino que ingresó al análisis e hizo un estudio de impacto de las consecuencias. En los casos anteriores, el Tribunal desestimó las solicitudes por falta de formalidades o por no observar el principio de subsidiariedad, que implica agotar primero las instancias anteriores (Pressemitteilung, 2020 $)^{16}$. Cabe observar que, si bien en el caso analizado el solicitante no agotó las instancias anteriores, el Tribunal entendió que tal requisito resultaba inútil, ya que los tribunales inferiores se habían expresado en otras oportunidades por la negativa a dictar medidas cautelares. De esta forma, sin recurrir a otros tribunales, el solicitante se dirigió directamente al Tribunal Constitucional.

\section{La decisión del Tribunal}

El tribunal reconoció que las medidas prohíben los contactos físicos inmediatos, los encuentros personales, el funcionamiento de centros de reunión de personas y abandonar los hogares sin motivos específicos (Beschluss 1 BvR 775/20 - Rn. 9). Consecuentemente, al analizar el impacto que tendría levantar las medidas, observó que de ser así, volverían a abrir los negocios cuya economía se ve afectada, las personas dejarían sus hogares con mayor frecuencia, y aumentarían los contactos directos entre personas (Beschluss 1 BvR $775 / 20$ - Rn. 10). Junto a ello aumentaría considerablemente el riesgo de contagio del virus, de enfermedad en muchas personas, de sobrecarga de las instituciones sanitarias, y lo que es aún peor, de muerte de personas (Beschluss 1 BvR 775/20 - Rn. 10).

Asimismo, el tribunal determinó cuales serían los argumentos a favor y en contra, de adoptar la medida solicitada. A favor: entendió que las medidas del Gobierno afectan la libertad de las personas y limitan los derechos fundamentales, teniendo incluso consecuencias irreversibles en lo social, cultural y económico (Beschluss 1 BvR 775/20 - Rn. 9). En contra: entendió que de levantarse las medidas, aumentarían las contagios, y las muertes, y por otro lado, que no está comprobado que la continuación de las consecuencias de las medidas de protección sean tan insostenibles, como para derogarlas, sabiendo que es una normativa temporal (Beschluss 1 BvR 775/20 - Rn. 11).

Hecha la evaluación, y pese a reconocer la afectación de derechos fundamentales por parte de las medidas adoptadas por el Gobierno de Baviera, el Tribunal rechazó la solicitud. Entendió que los peligros a la salud y a la vida son más graves que las limitaciones a la libertad personal (Beschluss 1 BvR 775/20 - Rn. 11). En su argumentación, el Tribunal refirió que las medidas de protección son extremas, pero aceptables, toda vez que fueron impuestas para lograr la protección de la salud y la vida, lo que a su vez es un deber constitucional para el Estado; y remarcó que se trata de medidas transitorias, y que para tales restricciones se prevén numerosas excepciones. (Beschluss 1 BvR 775/20 - Rn. 11). 
Finalmente, concluyó que: En razón a la importancia de los intereses en juego es razonable suspender ciertos derechos con carácter temporal para permitir una protección lo más amplia posible de la salud y de la vida, a la que el Estado está obligado en función al deber de protección ${ }^{17}$, establecido en el art. 2 inc. 2 de la Ley Fundamental (Beschluss 1 BVR 775/20 - Rn. 11).

\section{Conclusión}

Como sucede en este tipo de procesos, el Tribunal realizó una evaluación de impacto. En el caso particular, evaluó las desventajas que tendría el solicitante en caso de que su recurso al final prospere, pero manteniendo las medidas de protección en vigor hasta ese momento. Y luego comparó tales circunstancias, con lo que implicaría derogar las medidas impugnadas, sin prosperar el proceso principal iniciado por el solicitante.

Debido al carácter sumamente estricto del análisis de impacto que realiza el Tribunal, los procesos de urgencia en los que se derogan disposiciones son excepcionales. Ello en razón a que no basta con probar la sola gravedad de las medidas atacadas, ni la eventual probabilidad de éxito de un recurso de inconstitucionalidad, sino que debe probarse que las consecuencias de mantenerlas, serán peores que las de derogarlas.

En el caso analizado el recurrente no logró el éxito de su reclamo, porque el Tribunal hizo prevalecer el deber constitucional de protección a la vida y la salud que pesa en cabeza del Estado, por sobre los derechos fundamentales que se vieron restringidos. Y si bien, puede existir discusión en relación al alcance de las medidas que el Estado adopta, no hay dudas de que en el cumplimiento del deber de protección, y para efectivizarlo, éste debe organizar el ordenamiento jurídico, tarea en la que se sirve de la legislación (Chirstian Calliess, 2006).

Por último, resulta importante remarcar que en procesos de carácter urgente ante el Tribunal Constitucional Federal Alemán, en caso de admisión, se debe también resolver el fondo de la cuestión. Sin embargo este no fue el caso, razón por la cual el Tribunal remarcó que se pronunciará sobre el recurso de inconstitucionalidad más adelante.

\section{REFERENCIAS BIBLIOGRÁFICAS}

- Antoni Trilla, (2020) Un mundo, una salud: la epidemia por el nuevo coronavirus Covid 19. Disponible en: https://doi.org/10.1016/j.medcli.2020.02.002

- Bayerische Verordnung über eine vorläufige Ausgangsbeschränkung anlässlich der Corona-Pandemie vom 24. März 2020. Disponible en: https://www.verkuendung-bayern.de/baymbl/2020-130/

- Bayerische Verordnung über Infektionsschutzmaßnahmen anlässlich der Corona-Pandemie (Bayerische Infektionsschutzmaßnahmenverordnung - BaylfSMV) vom 27. März 2020. Disponible en: https://www.verkuendung-bayern.de/baymbl/2020-158/ 
- Bayerisches Infektionsschutzgesetz. Disponible en: https://www.verkuendung-bayern. de/gvbl/2020-174/

- Bekanntmachung des Bayerischen Staatsministeriums für Gesundheit und Pflege und des Bayerischen Staatsministeriums für Familie, Arbeit und Soziales vom 16.03.2020.

Disponible en: https://www.verkuendung-bayern.de/baymbl/2020-143/

- Bundesverfassungsgerichtsgesetz. Disponible en: https://www.gesetze-im-internet.de/ bverfgg/

- BverfG, (2020) Beschluss der 3. Kammer des Ersten Senats vom 7. April 2020 - 1 BvR 755/20. Disponible en: https://www.bundesverfassungsgericht.de/

- Christian Calliess, (2006) Die grundrechtliche Schutzpflicht im mehrpoligen Verfassungsrechtsverhältnis. Juristen Zeitung 61. Jahrg., Nr. 7 (7. April 2006), pp. 321-330.

- Gesetz zur Verhütung und Bekämpfung von Infektionskrankheiten beim Menschen (Infektionsschutzgesetz-IfSG). Disponible en: https://www.gesetze-im-internet.de/ifsg/

- Gobierno de Argentina (Página oficial). www.argentina.gob.ar/salud/coronavirus

- Grundgesetz Für die Bundesrepublik Deutschland (GG). Disponible en: https://www. gesetze-im-internet.de/gg/

- Klaus Michael Miebach, (2001) El federalismo en la República Federal de Alemania. 112001 / Política interior. Código 710 Q 1163. Disponible en: https://www.bivica.org/files/ Alemania-federalismo.pdf

- Ministerio de Salud de Alemania (Página oficial). www.bundesgesundheitsministerium.de

- Organización Mundial de la Salud (OMS). https://www.who.int

- Pressemitteilung Nr. 23/2020 vom 8. April 2020 https://www.bundesverfassungsgeri-

cht.de/SharedDocs/Pressemitteilungen/DE/2020/bvg20-023.html 